\title{
GREVE DOS CAMINHONEIROS: DIREITO DO TRABALHO COMO FERRAMENTA DE REGULAÇÃO SOCIAL
}

STRIKE OF TRUCKERS: LABOR LAW AS A TOOL FOR SOCIAL REGULATION

Marcelo BRAGHINI ${ }^{1}$

Andréia Martin SIMON²

ISSUE DOI: 10.21207/1983.4225.v15.n1.2020.831

\begin{abstract}
RESUMO
No contexto da Reforma Trabalhista promulgada por intermédio da Lei n. 13.467/17, discute-se os desafios decorrentes da greve dos caminhoneiros ocorrida em 2018 no Brasil, em razão do evidente retrocesso social representado pelo movimento de flexibilização legal, paulatinamente, adotado pelo
\end{abstract}

\footnotetext{
${ }^{1}$ Professor Titular Concursado de Direito do Trabalho e Processo do Trabalho da Universidade do Estado de Minas Gerais (UEMG). Doutorando em Direito Pela Universidade de Ribeirão Preto (UNAERP), Ribeirão Preto/SP. Graduado em Direito pela Universidade de Ribeirão Preto (1999), pósgraduado em Direito do Trabalho pela Pontifícia Universidade Católica de Goiás (2006), e em Direito Tributário pelo Instituto Brasileiro de Direito Tributário (2010), Mestre em Direito Constitucional pela Universidade de Ribeirão Preto. Professor de Direito do Trabalho e Processo do Trabalho pela Unaerp. Autor do livro: "Reforma Trabalhista: flexibilização das normas sociais do trabalho", 2017, pela editora LTr. Contato: marcelo.braghini@uemg.br. http://lattes.cnpq.br/0758745102492628.

2. Professora designada do Curso de Direito da Universidade do Estado de Minas Gerais (UEMG). Doutora em Direito Constitucional pela Pontifícia Universidade Católica de São Paulo/SP (PUC/SP). Mestra em Direito, pela Instituição Toledo de Ensino em Bauru (ITE). Especialista em Justiça Constitucional pela Universidade de Pisa (Itália). Bacharela em Direito pelo Centro Universitário de São José do Rio Preto/SP (2002). Advogada inscrita na Ordem dos Advogados do Brasil - Secção de São Paulo - sob o n. 216.485. Líder do Grupo de Pesquisa, certificado pelo CNPQ: IRIS (Igualdade, Reconhecimento e Inclusão Social: Minorias e Grupos Vulneráveis). Tem experiência acadêmicaprofissional em gestão de educação superior, tutoria em educação a distância e docência do ensino superior. Contato: andreiagarciamartin@gmail.com. http://lattes.cnpq.br/5843968752917552.
} 
legislador pátrio, concomitante com a desarticulação do sistema sindical, não havendo soluções eficientes a medida que o Direito do Trabalho não seja utilizado como ferramenta de regulamentação social. A pesquisa vale-se do tipo de pesquisa bibliográfica e documental; pelos tipos de raciocínio indutivo e analógico. Com o intuito de tornar possível uma alternativa legal e doutrinária com vistas a superar a crise instalada e promova equilibrio e equidade contratual.

Palavras-chave: Direito do Trabalho; Ferramenta de regulamentação social; Greve dos Caminhoneiros; Reforma Trabalhista.

\begin{abstract}
In the context of the Labor Reform promulgated through Law no. 13.467 / 17 discusses the challenges arising from the truck drivers' strike in Brazil in 2018, due to the evident social retrogression represented by the legal flexibilization movement, gradually adopted by the country legislator, concomitant with the disarticulation of the trade union system. efficient solutions as Labor Law is not used as a social regulation tool. The research is based on the type of bibliographic and documentary research; by the types of inductive and analogical reasoning. In order to make possible a legal and doctrinal alternative in order to overcome the installed crisis and promote balance and contractual equity.
\end{abstract}

Keywords: Labor Law; Social regulation tool; Strike of the Truckers; Labor Reform.

\title{
INTRODUÇÃO
}

A contextualização atual do direito do trabalho denota a necessidade de novas soluções para uma regulamentação mais eficiente da relação de poder estabelecida entre capital e trabalho, em especial pela crescente e inexorável informalidade do mercado do trabalho, bem como pela crise de identidade vivenciada pelos Sindicatos, não havendo articulação institucional capaz de reverter os níveis de ocupação que decorrem do desemprego estrutural, sem deixar de considerar um movimento tecnológico sem precedentes com profundos reflexos nas estruturas econômicas já tradicionais. Por evidente, modelos de negócios que tradicionalmente sempre empregaram grandes contingentes de trabalhadores, passam a estar com os dias contados, dentro da dinâmica apresentada por uma economia disruptiva no contexto de uma $4^{\mathrm{a}}$ Revolução Industrial.

No plano político, com o fim da Guerra Fria, representada pela simbologia por detrás da queda do muro de Berlim, não há mais a polarização ideológica entre o socialismo e o capitalismo. A inviabilidade prática do primeiro o relegou ao campo da utopia, enquanto o segundo encontra-se renovado pela vertente neoliberal.

Assim, diante dos desequilíbrios orçamentários provocados pelo Estado Social (Welfare State), motivos pelos quais reforça-se a tese de 
desregulamentação no sentido da desarticulação do direito do trabalho, discute-se a necessidade de um Estado suficientemente forte para fazer prevalecer os direitos mínimos de proteção do trabalho, que atrelados à fundamentalidade principiológica e valorativa, construídos ao entorno da dignidade da pessoa humana, fomenta-se a tutela da força normativa dos princípios constitucionais.

É inegável, que no contexto de uma sociedade de consumo, há uma exigência latente dos níveis de produtividade das empresas, acompanhado de ciclos econômicos de maior brevidade, que sejam compatíveis com um novo modelo de produção de bens e serviços. Este cenário, encontra-se alinhado com uma organização empresarial horizontal e flexível nos moldes Toyotistas, representando um redimensionamento da hierarquia inerente ao modelo Fordista de produção e a descentralização das atividades secundárias da empresa; sendo que a maximização do grau de especialização esteja na essência do ideal da terceirização, evidente subproduto do processo de globalização.

Todavia, não devemos nos descuidar da perspectiva histórica responsável pela construção do nosso atual modelo de proteção social. Pois, refletir a respeito dos erros e acertos, é compreender o próprio processo cultural responsável pela construção de nosso tecido social. Vez que, não há fórmula mágica a ser imposta por organismos internacionais dentro da perspectiva neoliberal do consenso de Washington (equilíbrio orçamentário, direito do trabalho mínimo, privatizações, regimes previdenciários auto-sustentáveis etc).

Eis que, devemos ser intérpretes capazes de extrair da norma a efetividade dos direitos fundamentais de segunda dimensão, em especial pela visão pós-positivista, bem como captar a essência da reforma do Código Civil de 2002, admitindo a construção doutrinária do Direito Civil Constitucional. Uma vez que a guinada promovida nesta seara do direito esteve sustentada nos preceitos da: eticidade, socialidade e operabilidade.

Em nossa ótica, uma reforma trabalhista, aqui idealizada por intermédio do constante movimento de flexibilização legal, representado pela neutralização da relação de emprego em favor da ampliação das relações de trabalho, deve reafirmar os valores essenciais do caput do art. 170 da CF/88, preservando na ordem econômica as dimensões do capitalismo idealizado no contexto do Estado Social.

Ora, percepções admitidas no sentido de que a ação interventiva do Estado na seara da livre iniciativa deve ir até o ponto de resguardar as 
condições mínimas de trabalho digno, e pelo viés do moderno Direito Econômico, são essenciais para compreendermos que devemos abandonar por completo a visão obtusa de que um progresso social represente um obstáculo, um entrave, ao desenvolvimento econômico, devemos admitir o avanço deste sem o preço de anularmos o primeiro.

Estas são as diretrizes do modelo constitucional atual a ser preservado: "a ordem econômica, fundada na valorização do trabalho humano e na livre iniciativa, tem por fim assegurar a todos a existência digna, conforme os ditames da justiça social [...] (art. 170, caput, Constituição Federal de 1988.

Por esta contextualização, a presente pesquisa toma como problemática a questão socio-trabalhista que praticamente "parou" o país em 2018, que foi a greve dos caminhoneiros.

Portanto, em nossas análises, intencionamos refletir sobre erros das políticas públicas adotadas na contemporaneidade no contexto de um pseudo Estado Social, representadas pelo movimento da flexibilização legal que patrocina um novo modelo de normatização social.

Neste sentido, vislumbrada tal análise, no sentido da privatização dos espaços normativos que permeiam às relações de trabalho, por inversão do processo do imperialismo da relação de emprego, com precarização das condições de trabalho e retrocesso social, agravado pela desarticulação sindical no âmbito das relações de trabalho, repuamos que o vácuo responsável pelo impasse vivenciado durante a greve dos caminhoneiros ocorrida no primeiro semestre de 2018 no Brasil, e nas vezes em que o Estado relega o protagonismo do Direito do Trabalho como eficiente instrumento de regulação social, é aquele que se recorre de soluções anacrônicas, que reforçam nossa predileção pela "jabuticaba".

Neste trabalho utilizamos o tipo de pesquisa bibliográfica e documental, vez que nos valemos da análise de doutrinas e pesquisas científicas sobre a temática, bem como de materiais disponíveis em veículos de informação de ampla divulgação. O tipo de raciocínio utilizado foi o indutivo e o analógico. Pois, considerando o caso específico da greve dos caminhoneiros, buscamos o intento de abranger a todos os casos semelhantes, que enquadrando-se numa relação de trabalho, e, portanto, mais ampla que a definida como relação de emprego, pretendemos demonstrar a possibilidade de aplicação das regras do Código Civil, como forma de assegurar uma tutela adequada relação de trabalho. 


\section{CICLO EVOLUTIVO DA CONSTRUÇÃO DO DIREITO DO TRABALHO}

Não há dúvidas de que o direito consiste em uma realidade histórico-cultural, o que nos permite a exata compreensão do desenvolvimento do direito do trabalho no curso da história, permitindo uma visão crítica quanto à tentativa de desarticulação do direito do trabalho, sob a justificativa de ter produzido níveis de proteção hoje anacrônicos.

A construção do direito do trabalho ao longo da história tem origem na fórmula inovadora utilizada à época para a inserção do trabalhador no sistema produtivo por intermédio da relação de emprego, motivo pelo qual não existiam traços do direito do trabalho nos antecedentes históricos.

As antigas corporações de ofício foram abolidas, na França, pela disposição do art. $1^{\circ}$ da Lei de Chapelier de 1791: "a eliminação de toda a espécie de corporação de cidadãos do mesmo estado ou profissão é uma das bases essenciais da Constituição Francesa, ficando proibido o seu restabelecimento sob qualquer pretexto ou forma"3 - promulgada no contexto da Revolução Francesa, e com suporte teórico no liberalismo (laissez faire, laissez passer, laissez aller), que promove a liberdade individual, sem a existência de corpos intermediários entre o indivíduo e o Estado que possam controlar o mercado e a concorrência.

A Revolução Francesa, ${ }^{4}$ em 1789, promoveu o liberalismo político e econômico, fundamentada no princípio da autonomia da vontade, não-intervenção do Estado nas relações privadas e livre atuação dos agentes econômicos no mercado, movimento histórico e cultural com suporte teórico nas lições de Adam Smith que revela e fomenta o espírito liberal-individualista, decorrência direta da Declaração Universal dos

\footnotetext{
${ }^{3}$ BRASIL. Universidade Federal de Minas Gerais. Lei Le Chapelier (1791) (14 de junho). Tradução de Luiz Arnaut. Disponível em: http://www.fafich.ufmg.br/hist_discip_grad/LeiChapelier.pdf. Acesso em: 08 out. 2018.

${ }^{4}$ Segundo Amauri Mascaro Nascimento embora a Revolução Francesa tenha sido a base para o florescimento do direito do trabalho, pela indispensabilidade do trabalho livre no seu processo de construção legal e doutrinária, a Revolução Francesa por si só não favorece o direito do trabalho em relação aos níveis de proteção almejados, este movimento mundial teve por fundamento a ideia de liberdade absoluta do homem na procura do seu próprio interesse, sem a interferência do Estado.(NASCIMENTO, Amauri Mascaro. Direito contemporâneo do trabalho. São Paulo: Saraiva, 2011, p. 54).
} 
Direito do Homem e do Cidadão $1789^{5}$ - segundo o seu Art.1 “ "Os homens nascem e são livres e iguais em direitos. As distinções sociais só podem fundar-se na utilidade comum", contudo, estamos diante de uma igualdade meramente formal perante a lei.

Com a Revolução Industrial ocorrida na Inglaterra no Século $\mathrm{XVIII}^{6}$, houve uma transição da sociedade artesanal para uma sociedade industrial, ganhos de produtividade e eficiência a partir da proposição liberal da divisão do trabalho ${ }^{7}$ - como ferramenta de racionalização do sistema de produção - proposta por Adam Smith na célebre obra " $A$

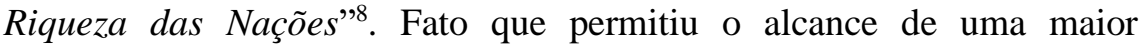
produtividade através da especialização de tarefas ${ }^{9}$, tornando-as deveras

\footnotetext{
5 (FRANÇA. Declaração Universal dos Direitos do Homem e do Cidadão. 1789. Disponível em: http://www.dhnet.org.br/direitos/anthist/dec1793.htm. Acesso em: 02 out. 2018). É de extrema importância o papel exercido pelas das declarações de diretos, por tratar-se de raros documentos sobre os quais há um consenso unânime, permitindo a construção de uma "consciência universal" com o viés de universalidade.

${ }^{6}$ Não por acaso que Daron Acemoglu e James A. Robinson, na obra "Why nations fail: the origins of Power, posperity, and poverty" 6 , reconhece que a Revolução Industrial encontra solo fértil na Inglaterra, a Revolução Gloriosa de 1651 foi indispensável neste sentido, eis que a limitação dos poderes do Rei permitiu o florescimento de uma sociedade pluralista a partir da ascensão da burguesia em relação aos meios de produção, com o fomento e implantação de uma série de instituições econômicas indispensáveis aos avanços absorvidos pelo setor produtivo, com destaque para a proteção dos direitos de propriedade via regime de exploração das patentes das invenções, incentivando James Watt na criação das máquinas a vapor, novas oportunidade que surgiam com a inovação aptas a franquear uma maior lucratividade. (ROBINSON, James A. Why nations fail: the origins of Power, posperity, and poverty. New York: Crown Business, 2012, p. 102).

${ }^{7}$ Francis Fukuyama, na obra "Political Order and Political Decay: from the Industrial Revolution to the Globalization of Democracy", destaca o impacto da divisão do trabalho na sociedade industrial, como fundamento econômico no vertiginoso crescimento vivenciado a partir da sociedade industrial, o que foi possível através da especialização de tarefas, após a decadência da sociedade artesanal, aumentando sensivelmente a produtividade das fábricas de manufaturados, as tarefas não são mais realizadas por um único homem, que a partir de Henry Ford permite a incorporação da produção em massa, com a implantação da linha de produção, como notórios ganhos de escala. (FUKUYAMA, Francis. Political order and political decay: from the industrial revolution to the globalization of Democracy. New York: FSG books, 2014, p. 44).

${ }^{8}$ Cf. SMITH, Adam. A riqueza das nações. 2. ed. São Paulo: WMF Martins Fontes, 2013, p. 8.

${ }^{9}$ Sob um viés lúdico, uma hipótese de alegoria da A divisão do trabalho é retratada no filme "Fome de Poder" estrelado por Michael Keaton, de 2017, retrata a inovação promovida pelos irmãos Richard e Maurice Macdonalds, que desenvolveram um novo modelo de negócios que viria a se tornar um padrão nos restaurantes de fast-food como conhecemos na atualidade, através da implantação de uma "cozinha modulada", imprimindo um ritmo Fordiano a uma simples atividade de preparação de hambúrgueres, servidos em questões de minutos, uma revolução à época. Os restaurantes, com origem em San Bernardino na Califórnia, por meio de um eficiente sistema de franquias implantado por Ray Kroc (messias do capitalismo e arauto dos valores ultra-liberais da "meritocracia" - "self made man"), vem a tornar-se um símbolo cultural em todas as partes do globo. (FOME de Poder (Nome Original: The Founder). Direção: John Lee Hancock. Produção: Aaron Ryder, Don Handfield e Jeremy Renner. Interpretes: Michael Keaton, Laura Dern, Patrick Wilson e Linda Cardellini. Roteiro: Robert Siegel. [S.I.]: FilmNation Entertainment, 2017. 1 bobina cinematográfica, $115 \mathrm{~min} ., 35 \mathrm{~mm}$ )
} 
simplificada que não ocasione a perda de tempo e amplie a destreza do trabalhador, evitando a troca de atividade relacionada com a manufatura de um mesmo produto - tarefa complexa subdividida em diversas etapas mais simples - pedra angular da estruturação do sistema produtivo com o emprego maciço de máquinas.

Obviamente que os ganhos de escala inerentes a sociedade industrial e de consumo, com a proporcional perda do poder de barganha dos empregados, estão atrelados ao maquinismo ${ }^{10}$ representado no processo de substituição da força de trabalho especializada e artesanal, utilização da força propulsora das máquinas, com a utilização de mão-deobra não qualificada, neste momento, a situação de superexploração do trabalhador atingia principalmente as crianças e mulheres, denominados de "meias-forças dóceis", com aumento significativo da incidência dos acidentes de trabalho.

\section{SOCIEDADE INDUSTRIAL}

A Revolução Industrial ocorrida na Inglaterra no Século XVIII está intrinsecamente relacionada com a origem do direito do trabalho, este representa a reação a uma situação de superexploração do trabalhador, submetido a condições de trabalho degradantes, com jornadas de trabalho ditadas pelo máximo da resistência física e mental do indivíduo, e o aviltamento dos salários na exata proporção da concorrência de mercado imposta ao trabalho braçal.

A gênese da construção legislativa e doutrinária do Direito do Trabalho está centrada no trabalho livre, que consiste no seu pressuposto histórico-material. Neste momento, a burguesia passa a ser a detentora dos meios de produção, permitindo a inserção do trabalhador através do arquétipo padrão da prestação de serviço subordinado, e por sua vez, o trabalho livre representa o "sopro de legitimidade" do novo sistema de valores que passa a suportar o Estado Moderno.

\footnotetext{
${ }^{10} \mathrm{O}$ marco histórico não está na criação ou invenção da máquina a vapor por James Watt (1765), do tear mecânico por Edmund Cartwright (1784), ou mesmo, o lampião a gás por Willian Murdock (1792), mas na sua aplicação na indústria, cunhando o conceito da Grande Indústria, que permite a desumanização e despersonalização do trabalhador, construção do conceito social referente ao proletariado, termo cunhado com a finalidade de designar o trabalhador submetido a jornadas extenuantes e sem a oportunidade do desenvolvimento intelectual.
} 
No campo jurídico, dever-se-á levar em consideração o contexto histórico-social ressaltado por Maurício Godinho Delgado ${ }^{11}$, uma vez que o direito vigente à época estava fundamentado no direito civil de formação liberal-individualista, sem a possibilidade de prover uma resposta jurídica adequada ao fato novo; ou seja, a matriz civilista clássica tendia a reduzir todas as questões surgidas no interior da relação de emprego em questões típicas do velho modelo do contrato bilateral.

Ademais, Alice Monteiro de Barros ${ }^{12}$ destaca a presença do individualismo latente do Código de Napoleão de $1804^{13}$, ao dispor no seu art. 1.134 que: "as convenções têm força de lei para os que as celebraram", sendo a partir desta gênese que houve a necessidade de uma intervenção do Estado nas relações privadas; que, denominada de dirigismo contratual, passa a ter uma variação de intensidade de acordo com a época e as contingências internas de cada povo. Na vertente social, ressaltamos a agitação dos trabalhadores em prol de melhores condições de trabalho, uma incipiente ação coletiva capaz de formatar o perfil orgânico e institucional dos Sindicatos.

Neste sentido, segundo o entendimento de Mário de La Cueva, estes movimentos operários atraíram a intervenção do Estado como manobra política para refrear o pensamento socialista, que ganhava corpo no seio da união dos trabalhadores. Em sua gênese, os Sindicatos foram identificados como um movimento clandestino e marginal, reconhecido oficialmente a partir de 1871 pelo movimento do tradeunionismo, uma associação de trabalhadores instituída para a defesa dos interesses comuns, apresentado como uma força social modeladora dos contornos protetivos do direito do trabalho. ${ }^{14}$

\footnotetext{
${ }^{11}$ DELGADO, Maurício Godinho. Curso de direito do trabalho. 13. ed. São Paulo: LTr, 2014, p. 91.

${ }^{12}$ BARROS, Alice Monteiro de. Curso de direito do trabalho. 10. ed. São Paulo: LTr, 2016, p. 53.

${ }^{13}$ Convém ressaltarmos que Francis Fukuyama, na obra "Political Order and Political Decay: from the Industrial Revolution to the Globalization of Democracy", em outra ponta, destaca a importância do Código de Napoleão de 1804 ao admitir um conceito moderno de fruição da propriedade, o que à época veio a representar a própria evolução do conceito da economia de mercado, vejamos o texto original: "The new Civil Code enshrined modern concepts of property rights: 'the right to enjoy and dispose of one's property in the most absolute fashion, provided that it is not used in a manner prohibited by law'. Land was freed of feudal and customary entails, opening the way for development of a market economy". (FUKUYAMA, Francis. Political order and political decay: from the industrial revolution to the globalization of Democracy. New York: FSG Books, 2014, p. 16).

${ }^{14}$ Cf. DE LA CUEVA, Mário. El nuevo derecho mexicano del trabajo. México, Porrúa, 1972. Em complemento, Amaury Marcaro Nascimento, conjectura que "O reconhecimento oficial dos sindicatos, na Inglaterra, deu-se em 1871, com a Lei dos Sindicatos. Floresceu o "tradeunionismo". Na França, em 1884, com a lei de Waldeck-Rousseau, permitindo às pessoas da mesma profissão ou de profissões conexas constituírem-se livremente em associações sem autorização do governo, desde que os seus
} 
Com efeito, torna-se importante a expressão cunhada por Evaristo de Morais Filho ${ }^{15}$ no sentido de que: "os sindicatos são a exteriorização jurídica de corpos sociais autônomos”.

\section{$4 \quad$ LIBERALISMO ECONÔMICO}

Com fundamento nos ideais da Revolução Francesa e centrado no plano teórico sobre a liberdade de contratação, o Estado de índole liberal portava-se como um mero espectador do desenvolvimento das relações privadas em geral, inspirado na fórmula de Vicent Gournay no laissezfaire, laissez-passer, com função de garantir apenas a ordem social e política $^{16}$, e assegurando aos particulares uma ampla liberdade de ação econômica.

Nota-se a evidente decadência do sistema liberal ao assegurar uma igualdade jurídica meramente formal, perante a lei, para regular uma relação social inserida em contexto de notória desigualdade econômica, a liberdade de contratar não sofria quaisquer restrições pelo Estado a pretexto da preservação da autonomia da vontade em matéria contratual, uma igualdade jurídica insubsistente diante da desigualdade econômica.

Neste contexto histórico, o individualismo entranhado nos fundamentos do direito clássico estava umbilicalmente ligado a proteção irrestrita da propriedade, centrado na proteção patrimonial dos bens materiais ao arrepio das concepções humanistas desenvolvidas a partir da

objetivos fossem exclusivamente a defesa dos interesses profissionais e econômicos". (NASCIMENTO, Amauri Mascaro; NASCIMENTO, Sônia Mascaro. Curso de direito do trabalho: história e teoria geral do direito do trabalho: relações individuais e coletivas do trabalho. 29. ed. São Paulo: Saraiva, 2014, p. 32).

${ }^{15}$ MORAIS FILHO, Evaristo de. O problema do sindicato único no Brasil: seus fundamentos sociológicos. 2 ed. São Paulo: Alfa-Omega, 1978, p. 103.

${ }^{16}$ A partir deste momento histórico presenciamos a construção do princípio do rule of law, com a finalidade de limitar o poder político do Monarca, que passava a submeter-se às mesmas regras de conduta aplicáveis aos seus súditos, e para Francis Fukuyama na obra "Political Order and Political Decay: from the Industrial Revolution to the Globalization of Democracy", o referido princípio teve origem na religião, uma vez que as autoridades religiosas em muitas culturas eram responsáveis pela interpretação dos textos sagrados, introduzindo as sanções morais sobre toda a sociedade, com a capacidade de criar regras de condutas respeitadas pelos próprios guerreiros. O rule of law foi institucionalizado na Europa Ocidental através do papel desempenhado pela Igreja Católica que teve a prerrogativa da revisão do Direito Romano lastreado no instrumento do Corpus Juris Civilis de Justiniano, que na Inglaterra encontra uma tradição legal sustentada nos precedentes do Common Law. (FUKUYAMA, Francis. Political order and political decay: from the industrial revolution to the globalization of Democracy. New York: FSG Books, 2014, p. 16). 
essência do ser humano, que permita a existência, ao lado dos direitos patrimoniais, dos direitos de personalidade, de conteúdo moral, e alinhados com a importância alcançada pela dignidade da pessoa humana como substrato cultural sociedade contemporânea.

Segundo Eros Roberto Grau, a consagração constitucional do princípio da dignidade da pessoa humana, de profunda relevância, colocando o aspecto humanitário como epicentro do ordenamento jurídico, assume a maior relevância ao comprometer o exercício da atividade econômica, delineada a partir da perspectiva da promoção da existência digna, independentemente dos interesses individuais dos agentes econômicos que passam a desempenhar suas funções no mercado. ${ }^{17}$

A partir desta realidade social e política, Segadas Vianna citando Orlando Gomes ${ }^{18}$, esclarece quanto à necessidade de uma nova fórmula de regulamentação das relações de trabalho, identificando aqui a crise do direito vivenciada à época, incapaz de entender os fenômenos econômicos e sociais e, ao mesmo tempo, franquear uma solução justa e equilibrada que pudesse contemplar as reivindicações operárias por melhores condições de trabalho, talvez o mesmo que vivenciamos na atualidade em relação à ampliação da parassubordinação, com efeitos diretos na crescente informalidade do mercado de trabalho.

Devemos frisar que o contraponto ao liberalismo surge de suas próprias entranhas, uma releitura lastreada no seu próprio instinto de sobrevivência, especialmente no momento que o Chanceler Alemão Bismarck, compreende que a proteção ao trabalhador, por indução e interferência Estatal, passa a ser uma preocupação constante do próprio Capitalismo, diante do desenvolvimento impetuoso do pensamento socialista vivenciado à época, havendo através do contrato de trabalho, um discurso conservador, uma função ideológica no sentido da manutenção do status quo, do establishment, assegurando um resultado estável e duradouro na organização social da qual depende a sobrevivência do capitalismo.

Como contraponto ideológico, a doutrina Marxista expõe crítica ferrenha a este estado de coisas, promove a união dos trabalhadores para a construção da ditadura do proletariado, com a supressão do capital, através

\footnotetext{
${ }^{17}$ Cf. GRAU, Eros Roberto. A Ordem Econômica na Constituição de 1988.16. ed. São Paulo: Malheiros, 2013, p. 194.

${ }^{18}$ VIANNA, Segadas et al. Instituições de direito do trabalho. 17. ed. vol. 1. São Paulo: LTr, 1997, p. 38.
} 
da apropriação pelo Estado dos bens de produção, com a sistematização do coletivismo através da obra "O Capital", na qual Karl Marx ${ }^{19}$ e Friedrich Engels permitem a inserção do homem no conceito gregário reinante, através do fomento da expressão coletiva, disseminando a existência de uma personalidade/identidade coletiva ao entorno da causa operária.

O liberalismo pela perspectiva do direito social pode ser sintetizado na frase cunhada por Lacordaire, e proferida na Conferência de Notre-Dame em 1948: "Entre o forte e o fraco, entre o rico e o pobre, é a liberdade que escraviza, é a lei que liberta". ${ }^{20}$

Certamente a liberdade excessiva das "economias de mercado" teve por subproduto as condições sociais degradantes vivenciadas no transcorrer da Revolução Industrial, tornando necessário o desenvolvimento progressivo de uma legislação social de caráter protetivo, que possa arrefecer a dinâmica socialmente injusta, regida de forma exclusiva pela lei da oferta e da procura ${ }^{21}$.

Através da Conferência de Berlim realizada em 1890, começa a disseminar a ideia de internacionalização das normas fundamentais de proteção social do trabalho, como meio de nivelar os custos de produção entre os países industrializados, e ainda, alcançar os anseios de justiça social, intentados pelas reivindicações operárias à época, de modo que a regulamentação internacional das condições do trabalho pela Organização

\footnotetext{
${ }^{19}$ Charles Adams na obra intitulada: "For Good and Evil: The Impact of Taxes on the Course of Civilization", destacada que as condições de trabalho analisadas no aspecto ambiental e pós-revolução industrial, sob severas críticas por Marx, são sobejamente superiores àquelas vivenciadas nos satélites soviéticos da Europa Oriental em plena consecução da ideologia socialista, não havendo proposição de uma alternativa viável ao Capitalismo para além do discurso utópico, incapaz de romper a barreira do plano teórico. (Cf. ADAMS, Charles. For good and evil: the impact of taxes on the course of civilization. 2 ed. Madison Books: Maryland, 1999, p. 154).

${ }^{20}$ VIANNA, Segadas et al. Instituições de direito do trabalho. 17. ed. vol. 1. São Paulo: LTr, 1997, p. 92.

${ }^{21} \mathrm{Na}$ atualidade, o debate político e não menos ideológico a respeito do tamanho do Estado, é tratado de forma clara na entrevista de Zanny Minton Beddoes, editora chefe da revista britânica "The Economist", concedida ao Jornal Folha de São Paulo (Domingo, 21 de abril de 2016), traçando a exata diferença do liberalismo Inglês do americano, vejamos: "O Liberalismo inglês é muito diferente do americano. Na Inglaterra, o liberalismo se dá pela crença no mercado livre e nas liberdades individuais. Libertário é basicamente Estado mínimo, sem governo, e o extremo é o Estado que prevê polícia e nada mais. Não somos libertários, somos liberais: há papéis que o governo tem que ter, há áreas em que precisa atuar na busca pela liberdade individual". (ODILLA, Fernanda. Brasil paga agora por omissão do governo e erros na economia. In: Jornal Folha de São Paulo, Ano 96, n. 31.798. Caderno Mercado, 24 de abril de 2016, p. 21. Disponível em: http://dl6.booklan.ir/Newspapers/Portuguese/116-08-22-00/Ebook.pdf. Acesso em 08 out. 2018.
} 
Internacional do Trabalho, criada em 1919, passasse a representar uma pretensão universalista. $^{22}$

Ainda sob o viés histórico, Robert Peel, na Inglaterra em 1802, propõe a primeira lei de limitação de jornada do menor (talvez, para preservação de uma própria reserva da massa operária) e um regramento de higiene nas fábricas, através do seu "Moral and Health Act", sem muita efetividade prática, cabendo ao empresário Robert Owen, considerado por muitos o pai do direito do trabalho, a implantação de diversas medidas de proteção na sua fábrica de tecidos em New Lamarck, iniciativas retratadas na sua obra "A New View of Society" de 1813, incentivando as agremiações de empregados através dos trade unions (Sindicatos). ${ }^{23}$

\section{IMPERIALISMO DA RELAÇÃO DE EMPREGO}

O gênero trabalho, analisado pela perspectiva de uma prestação de serviço em favor de outrem, deve corresponder a toda energia física ou intelectual empregada pelo homem com finalidade produtiva. Dentro deste universo, é necessário delimitar nosso objeto de estudo, o que atrai a aplicação, em regra, das regulamentações dispostas na Consolidação das Leis do Trabalho (CLT), desde que caracterizada a relação de emprego, ou seja, a prestação subordinada do serviço, núcleo central de nossa disciplina. Excepcionalmente, e denotando o caráter expansionista do direito do trabalho, por disposição constitucional específica e não pela natureza da relação jurídica (art. $7^{\circ}$, inciso XXXIV, da CF), admite-se a aplicação das normas trabalhistas ao trabalhador avulso, relação jurídica assemelhada, na qual, não é possível identificar os elementos essenciais da relação de emprego.

A doutrina clássica analisando a construção Histórica do Direito do Trabalho ressalta a construção de uma nova fórmula para regulamentação das relações do trabalho, através do conceito técnico da relação de emprego, já que à época, o sistema jurídico absorveu os fundamentos políticos da vertente individualista e liberal, e o Código Civil de 1916 não avançou na questão social, dispondo de parca regulamentação destinada às regras de locação de serviços.

\footnotetext{
${ }^{22}$ SÜSSEKIND, Arnaldo. Direito internacional do trabalho. 3. ed. São Paulo: LTr, 2000, p. 18.

${ }^{23} \mathrm{Cf}$. MORAES FILHO, Evaristo de; MORAES, Antonio Carlos Flores de. Introdução ao direito do trabalho. 6. ed. São Paulo: LTR, 1993, p. 65 e ss.
} 
Neste sentido, nas palavras de Clóvis Bevilaqua, citado por Octavio Bueno Magano, a locação de serviços foi concebida como um contrato de grande amplitude compreendendo uma grande variedade de prestações de trabalho humano, sendo uma vala comum dos contratos de atividade. ${ }^{24}$

Posteriormente, com o efeito da promulgação da CLT em 1943, houve um esvaziamento do contrato de locação de serviços, diante de um verdadeiro "imperialismo" do contrato subordinado.

A partir daquela nova realidade social e política, Segadas Vianna citando Orlando Gomes ${ }^{25}$, esclarece quanto à necessidade de uma nova fórmula de regulamentação das relações de emprego, identificando aqui a crise do direito vivenciada à época, incapaz de entender os fenômenos econômicos e sociais e, ao mesmo tempo, franquear uma solução justa e equilibrada que pudesse contemplar as reivindicações operárias por melhores condições de trabalho, talvez o mesmo que vivenciamos na atualidade em relação à ampliação da parassubordinação, com efeitos diretos na crescente informalidade do mercado de trabalho.

O imperialismo da relação de emprego foi possível através da inegável redução do espaço para a aplicação das teorias da flexibilização, que perpassam por uma maior amplitude da autonomia negocial coletiva dos Sindicatos, que venham a refletir a vontade da categoria profissional envolvida e legitimada pela chancela da assembleia geral de trabalhadores.

Assim, nas palavras de Octavio Bueno Magno encontram obstáculo na hipertrofia do direito individual, e o grande perigo da tese da flexibilização está na existência de um aparato institucional capaz de promover o equilíbrio entre capital e trabalho, vejamos:

[...] nos sistemas jurídicos de tradição romano-germânica, em funcionamento nos países latinos, o direito individual do trabalho tem tomado a forma predominante de textos legais, ao passo que, nos países da "common law", tem-se consubstanciado, quase sempre, em cláusulas de convenção coletiva do trabalho. O fenômeno se explica por serem os Sindicatos mais fortes e mais atuantes nos países do segundo grupo a consequência do mesmo

\footnotetext{
${ }^{24}$ Cf. MAGANO, Octavio Bueno. Manual de direito do trabalho. Parte Geral. 2. ed. São Paulo: LTr, 1980, p. 35 .

${ }^{25}$ Cf. VIANNA, Segadas et al. Instituições de direito do trabalho. 17. ed. vol. 1. São Paulo: LTr, 1997, p. 38.
} 
fenômeno tem sido a hipertrofia do direito individual do trabalho, nos países do primeiro grupo. ${ }^{26}$ (grifou-se)

Desta forma, temos nos artigos $2^{\circ}$ e $3^{\circ}$ da CLT os elementos de ligação que permitem a transformação de uma relação social em relação jurídica socialmente protegida, diante da incidência automática de um conteúdo contratual mínimo, decorrente do fenômeno do dirigismo contratual, representando pelo conjunto de normas de ordem pública, imperativas, que em regra, não podem ser simplesmente derrogada pela vontade das partes contratantes, o que vem sendo negado pela tese da flexibilização legal, com progressivo esvaziamento do universo de trabalhadores protegidos pelo texto celetista, provocando o transbordo do trabalhador vulnerável para uma relação jurídica assimétrica constituída com fundamento na autonomia da vontade do direito civil.

\section{RETIPIFICAÇÃO CONTRATUAL PELA REAPROXIMAÇÃO COM O DIREITO CIVIL}

Antes mesmo das novas figuras jurídicas criadas com a Reforma Trabalhista (Lei n. 13.467/17), a doutrina reconhecia a necessidade da retipificação do contrato de trabalho no sentido da ampliação dos contratos a prazo, ${ }^{27}$ em especial diante da inexorável reabsorção de parcela das relações de trabalho pela prestação de serviço do Direito Civil.

Nesta toada, segundo Luiz Carlos Amorim Robortella ${ }^{28}$ através da revalorização dos contratos civis, a partir da retomada do diálogo entre o direito do trabalho e direito civil, tem-se o caminho inverso do imperialismo da relação de emprego pós-revolução industrial, as principais instituições responsáveis pela preservação dos direitos sociais dos trabalhadores postaram-se contra, em diversos aspectos.

Através do artigo publicado no jornal The New York Times, em setembro de 2017, como o título "A New Type of Labor Law for a New

\footnotetext{
${ }^{26}$ MAGANO, Octavio Bueno. Manual de direito do trabalho. Parte Geral. 2. ed. São Paulo: LTr, 1980, p. 16.

${ }^{27}$ Evidenciamos, assim que esta retipificação do contrato de trabalho já era neologismo utilizado por Amauri Mascaro Nascimento.Conforme nos informa Nelson Mannrich, Amauri Mascaro já havia termo utilizado este termo no V Congresso de Direito Individual da LTr em 1991. (Cf. MANNRICH, Nelson. A modernização do contrato de trabalho. São Paulo: LTr, 1998, p. 71).

${ }^{28}$ Cf. ROBERTELLA, Luiz Carlos Amorim. O direito do trabalho na empresa e na sociedade contemporânea. São Paulo: LTr, 2010, p. 28.
} 
Type of Worker", que trata a respeito de um novo tipo de lei para um novo tipo de trabalhador, já que não teremos mais o modelo padrão disseminado pelas fábricas e Sindicatos do passado, nos Estados Unidos da América os Sindicatos na esteira do movimento interventivo de estímulo econômico no New Deal foi responsável por forjar a realidade social representada pela classe média, mola propulsora de uma economia capitalista de consumo, induzindo o aumento de salários e ampliação dos benefícios. Não há, pela ausência das fábricas, um modelo homogêneo de gestão da força de trabalho, o que por si só enfraquece o poder de barganha do passado, a descentralização da força de trabalho foi acompanhada da centralização poder econômico e político das grandes corporações, reais empregadores, havendo a necessidade premente da reconstrução; ou melhor, da construção de novas organizações de trabalhadores, que tenham não o teto, mas o mínimo o básico como meta para o aperfeiçoamento das condições de trabalho, a exemplo de um valor mínimo pela hora de trabalho. ${ }^{29}$

Para Luiz Carlos Amorim Robortella ${ }^{30}$ a heterogeneidade do mercado de trabalho estimulado pelas novas tecnologias no contexto de uma sociedade da informação estaria por estimular o diálogo com o direito civil, afastando a visão monopolista da relação de emprego na regulamentação do trabalho, uma vez que o trabalho intelectual se mostra diuturnamente menos acomodável nos estreitos limites da relação de emprego.

\footnotetext{
${ }^{29}$ Texto original: “We can't hope to build a more equitable economy unless working people have strong organizations of their own. During and after the New Deal, unions were essential to forging a broad new middle class - not only because they raised wages and benefits, but also because they countered corporate and financial political power, which today is the greatest impediment to serious change". [...] Democratic lawmakers know that their party was founded on the proposition that concentrated wealth seeks to convert its economic power into political power and that left to its own devices, it puts our democracy at risk. A new workers' movement would also be a bulwark against the old Jeffersonian nightmare of rule by a self-perpetuating economic oligarchy. For both reasons, progressive lawmakers and policy analysts need to promote a new generation of labor organizations". [...] Second, our labor law holds businesses accountable only to the workers whom they "employ" in an old-fashioned, contractual sense. That too made sense in the industrial era, when leading companies had millions of employees. But today, janitors, Amazon delivery drivers and warehouse workers are often employed by subcontractors who have little real power over their livelihoods. And Uber and Lyft drivers are misclassified as independent contractors. As a result, these workers don 't have clear rights to bargain with the companies that actually set the rules. And these workers are subject to big restrictions on striking or picketing against such "third party" companies". (FORBATH, William E. Forbath; ROGERS, Brishen. A New Type of Labor Law for a New Type of Worker. In: The New York Times, Opinion - OP-ED CONTRIBUTORS, Nova York, 04 de setembro de 2017. Disponível em: https://www.nytimes.com/2017/09/04/opinion/labor-laws-workers.html. Acesso em 20 out. 2018).

${ }^{30}$ Cf. ROBERTELLA, Luiz Carlos Amorim. O direito do trabalho na empresa e na sociedade contemporânea. São Paulo: LTr, 2010, p. 28.
} 
Convém ressaltarmos que a conhecida MP do "Bem", que no art. 129, da Lei n. 11.196/95, admitia, para fins fiscais e previdenciários, a prestação de serviços intelectuais, por intermédio de pessoa jurídica, ainda que sobressaia o caráter personalíssimo de seus sócios, sujeitando-se tão somente a legislação aplicável às pessoas jurídicas.

Assim, partindo de uma análise do princípio da primazia da realidade às avessas, torna-se evidente a impossibilidade de se ignorar o avanço das empresas individualizadas, criadas por executivos extremamente bem remunerados, o que seria um movimento de regularização da pejotização.

Então, já que este caminho é inexorável no sentido da pejotização com o esvaziamento do contrato de trabalho, tutelado pela própria lei. Propomos, neste sentido, uma faixa de transição para a recepção deste trabalhador no plano residual da prestação do serviço, uma melhor recepção no Direito Civil, que na esteira do Direito do Consumidor, passa a estar atrelado a ideia da socialidade pelo dirigismo estatal. Atraindo a aplicação veemente dos preceitos jurídicos indeterminados, com destaque especial para a teoria do abuso do direito, preservando a finalidade social da disciplina legal. Pela compreensão de que o desequilíbrio econômico não autoriza a aplicação plena e irrestrita das regras que pressupõe a autonomia da vontade, própria da liberdade de contratar, nos cenários em que seja possível identificar a igualdade substancial da relação fática captada pela normatização do direito, persistindo o aspecto da vulnerabilidade do trabalhador.

Acreditamos no cuidado em que se deve tratar a transição do empregado para a prestação de serviços do direito civil, uma vez que o não enquadramento da relação jurídica na tipologia da relação de emprego, por vezes se dá por um pequeno detalhe, especialmente na zona "grise" da parassubordinação, e o trabalhador, não mais o empregado, recepcionado pelo Direito Civil preserva as características contratuais de assimetria contratual mesmo dentro de um contexto amplo da prestação do serviço em favor de outrem, admitida agora dentro do gênero trabalho, e desconsiderando o núcleo representado pela figura jurídica do trabalho subordinado (relação de emprego).

Portanto, na aplicação residual das normas disciplinadas no Código Civil que tratam da prestação do serviço, qual seja o art. 593, prevendo que: "A prestação de serviço, que não estiver sujeita às leis 
trabalhistas ou a lei especial, reger-se-á pelas disposições deste Capitulo".

Desta forma, haverá naturalmente a atração das regras representativas do dirigismo contratual responsável pelo contingenciamento da autonomia contratual em favor de uma maior equidade e equilíbrio contratual, expressados por meio dos seguintes preceitos jurídicos indeterminados: boa-fé objetiva (art. $113 \mathrm{c} / \mathrm{c} 422$ do CC); abuso de direito (art. 187 do CC); responsabilidade objetiva na atividade de risco (art. 927, § único, do CC); e, onerosidade excessiva dentro da perspectiva da teoria da imprevisão (art. 478, do CC) ou ainda, resilição contratual ${ }^{31}$ e enriquecimento sem causa ${ }^{32}$.

Neste ponto, temos razões de sobra para creditar à greve dos caminhoneiros, movimento de trabalhadores com profundas consequências no equilíbrio do contrato social ${ }^{33}$, ocorrida no primeiro semestre de 2018 no Brasil, seria um subproduto do movimento de flexibilização legal alcançado pela construção legal da figura jurídica do Transportador Autônomo de Carga previsto no art. $5^{\circ}$ da Lei n. 11.442/07 $7^{34}$. Eis que, enquadra-se em trabalhador vulnerável que passa a estar inserido em uma relação jurídica assimétrica, regulamentada timidamente pelo direito civil, neutralizando, como em demais iniciativas legais, o reconhecimento da relação de emprego pelo formalismo contratual restaurado, em contraste como o princípio da primazia da realidade positivado no art. $9^{\circ}$ da CLT.

Os efeitos não estão restritos ao campo do Direito do Trabalho, são infinitamente nefastos e perniciosos no contexto previdenciário, seja

\footnotetext{
${ }^{31}$ É o teor do artigo 473, do Código Civil: "A resilição unilateral, nos casos em que a lei expressa ou implicitamente o permita, opera mediante denúncia notificada à outra parte. Parágrafo único. Se, porém, dada a natureza do contrato, uma das partes houver feito investimentos consideráveis para a sua execução, a denúncia unilateral só produzirá efeito depois de transcorrido prazo compatível com a natureza e o vulto dos investimentos".

${ }^{32} \mathrm{O}$ Art. 884 prescreve que: "Aquele que, sem justa causa, se enriquecer à custa de outrem, será obrigado a restituir o indevidamente auferido, feita a atualização dos valores monetários. Parágrafo único. Se o enriquecimento tiver por objeto coisa determinada, quem a recebeu é obrigado a restituíla, e, se a coisa não mais subsistir, a restituição se fará pelo valor do bem na época em que foi exigido".

${ }^{33}$ Reconhecemos que parcela a imprensa independente tenha reconhecido à época da paralisação, uma articulação dos empresários do setor de transporte no sentido do lockout, pressão contrária ao sistema vigente de precificação dos insumo regulados pelo governo, como o óleo diesel e pedágio cobrado sobre eixo não utilizado, conduta abusiva e arbitrária vedada pelo art. 17 da Lei $n^{\circ} 7.783 / 89$ (Lei de Greve).

${ }^{34}$ In verbis: "Art. $5^{\circ}$ As relações decorrentes do contrato de transporte de cargas de que trata o art. $4^{\circ}$ desta Lei são sempre de natureza comercial, não ensejando, em nenhuma hipótese, a caracterização de vínculo de emprego. Parágrafo único. Compete à Justiça Comum o julgamento de ações oriundas dos contratos de transporte de cargas".
} 
pela predileção do sistema de custeio pelo modelo Bismarckiano, inclusivo apenas para a figura jurídica do empregado (relação empregatícia) e funcionário público, incidência das contribuições sobre a folha de salários - base de cálculo estável e que permite a racionalização do sistema de contribuição diante da posição privilegiada da fonte pagadora -, devendo a empresa ser a responsável legal pela retenção, com a inserção compulsória no sistema da figura jurídica do segurado obrigatório, ao qual são franqueados os serviços e benefícios de proteção, reconhecidos como riscos sociais elegíveis na lei previdenciária, e de pretensões universalistas.

$\mathrm{O}$ alerta foi feito por Fábio Zambitte Ibrahim, na obra " $A$ Previdência Social no Estado Contemporâneo, para quem:

[...] a empreitada começa pela sociedade de risco, a qual, entre vários aspectos, traz novas relações de trabalho, que diminuem o quantitativo dos contratos de emprego típicos, expondo novas vulnerabilidades e incrementando a pobreza. A sociedade de risco, ao mesmo tempo que impõe algum tipo de mecanismo de segurança social, demanda revisão dos paradigmas existentes, especialmente do modelo bismarkiano de previdência social, o qual, como se verá, foi originário de uma sociedade industrial que não mais existe..$^{35}$

Neste ponto, Aliomar Baleeiro, ${ }^{36}$ analisando a perspectiva orçamentária do Estado do bem-estar social, destaca os desequilíbrios orçamentários sucessivos exigidos dos países ocidentais para a manutenção desta teia de proteção social, alcançadas por intermédio das políticas públicas de Estado. Tais interferências são defendidas através da teoria Keynesiana, com reflexos econômicos à medida que se passa a tolerar um razoável déficit orçamentário nos períodos de crises econômicas, com ciclos cada vez mais curtos nos tempos atuais, de forma a injetar grandes somas de dinheiro na economia para o fomento do seu reaquecimento, com vistas ao pleno emprego, sempre sob a sombra do descontrole inflacionário, sem perder de vista o ponto de exaurimento do repasse das receitas derivadas, na forma de tributos, extraídos do patrimônio individual dos contribuintes.

\footnotetext{
${ }^{35}$ IBRAHIM, Fábio Zambbitte. A Previdência Social no Estado Contemporâneo. Rio de Janeiro: Impetus, 2011, p. 02.

${ }^{36}$ Cf: BALEEIRO, Aliomar. Uma introdução à ciência das finanças. 18. ed. Rio de Janeiro: Forense, 2012, p. 542.
} 
No contraponto, Amartya $\operatorname{Sen}^{37}$ destaca a importância da livre iniciativa diante da perspectiva orçamentária do Estado Social, eis que o desenvolvimento econômico fundado no direito de autodeterminação dos agentes privados, que atuam no mercado de bens e serviços, está atrelado às transações econômicas realizadas entre estes mesmos agentes, representando o grande motor do crescimento econômico amplamente aceito no mundo ocidental. Estas relações permanecem pouco reconhecidas e precisam ser mais plenamente compreendidas na análise das políticas públicas, uma vez que o crescimento econômico pode ajudar não só elevando rendas privadas, mas também possibilitando ao Estado financiar a seguridade social e a intervenção governamental ativa.

Com a promulgação da Lei n. 13.467/17 nota-se uma tendência flagrante de flexibilização legislativa, com a criação de alguns requisitos formais que permitam a neutralização de algumas relações sociais de trabalho com características da relação de emprego, numa verdadeira aplicação ao recurso às relações de trabalho lato sensu. Todas elas, sumariamente, por força de lei, fora do âmbito de proteção normativa intencionada pelo texto celetista, admitidas no mesmo plano hierárquico normativo (não obstante a discussão do Regime Constitucional do Emprego Social). Esta remodelação, para alguns, apresenta-se como uma exigência da própria evolução social, devendo o trabalho ser compreendido como elemento de integração do tecido social, sob pena do seu esgarçamento; sendo imprescindível a intervenção estatal para sua regulamentação, bem como o fomento de novos arquétipos justrabalhistas alternativos, desde que o legislador venha a calibrar adequadamente a dosagem do tecido protetivo, e não apenas relegando a relação social a regra residual da prestação do serviço.

Ao analisarmos a neutralização da relação de emprego no âmbito das cooperativas de trabalho do art. 442, § único, da CLT, estaria por evidenciar o vício da inconstitucionalidade sob o prisma dos valores sociais do trabalho estampados no art. $1^{\circ}$, inciso IV, da CF.

\footnotetext{
${ }^{37}$ Amartya Sen (SEN, Amartya. Desenvolvimento como liberdade. São Paulo: Companhia das Letras, 2010 p. 61) foi laureado com o Prêmio de Ciências Econômicas em Memória de Alfred Nobel de 1998, pelas suas contribuições à teoria da decisão social e do "welfare state". Amartya Sen lecionou na London School of Economics, Universidade de Oxford e Universidade de Harvard. Reitor da Universidade de Cambridge, é também um dos fundadores do Instituto Mundial de Pesquisa em Economia do Desenvolvimento (Universidade da ONU). Seus livros mais importantes incluem: "On Economic Inequality", "Poverty and Famines" e "On Ethics and Economics".
} 
Para Jorge Luiz Souto Maior, os efeitos do modelo cooperado no Brasil, que deveria representar apenas uma forma alternativa de organização do trabalho, com o arrefecimento do intuito meramente lucrativo no âmbito do sistema capitalista, e com inegável viés comunitário, vejamos:

\footnotetext{
Diga-se, ademais, que não é com a prestação de trabalho, mediante o sistema de cooperativas, sem formação de vínculo empregatício, que os trabalhadores irão alcançar melhores condições de vida, até porque, nesse sistema desvirtuado, os trabalhadores não deixam de ser meros prestadores de serviços, não participam da atividade econômica e não usufruem, portanto, livremente, o produto do seu trabalho. ${ }^{38}$
}

Ainda quanto aos impactos marcantes no redimensionamento do objeto do direito do trabalho, não há como deixar de registrar a tendência flexibilizante do legislador infraconstitucional ao neutralizar a relação de trabalho de forma pontual, movimento por nós reconhecido com flexibilização legal.

Ora, dentro de contextos contratuais que identificam os elementos fáticos jurídicos caracterizadores da relação de emprego, a previsão de um modelo alternativo que amplie sua alocação no campo residual do direito civil, estipulando critérios legais aptos a preservar a segurança jurídica do modelo intencionado, uma vez que no curso da história a positivação das regras jurídicas, sempre foi a forma de franquear previsibilidade ao custo de produção, previsibilidade esta, indispensável à manutenção do establishment representado pelo modelo capitalista da economia de mercado.

Em sentido contrário do movimento expansivo do direito do trabalho retratado na doutrina tradicional, a flexibilização legal promove, paulatinamente, o transbordo de trabalhadores transformados artificialmente em empresários, mas mantendo sua vulnerabilidade em relações jurídicas assimétricas, sem a intervenção do Estado Social na forma de dirigismo contratual.

No cenário da questão grevista, evidencia-se a impossibilidade de negociação do frete em igualdade de condições com os reais detentores do poder econômico do setor de transporte, que não influencia, mas controla a sua precificação, havendo inexoravelmente a precarização das

\footnotetext{
${ }^{38}$ SOUTO MAIOR, Jorge Luiz. O direito do trabalho como instrumento de justiça social. São Paulo: LTr, 2000, p. 324.
} 
condições de trabalho com retrocesso social, movimento agravado pela desarticulação completa de um modelo sindical artificial, construído a partir das bases conceituais da relação de emprego. Sendo que, ao final das negociações com o Governo Federal, houve extrema dificuldade de desarticulação do movimento, pela fragmentação das lideranças manifestadas na não convergência da pauta de reivindicações, comando exercido na história contemporânea pelos Sindicatos, órgão intermediário entre o Estado e a sociedade civil, que demonstra papel de elevado arrefecimento das reivindicações operárias.

\section{CONCLUSÃO}

Por todo o abordado nesta pesquisa, evidencia-se que talvez estejamos vivenciando não apenas o esgotamento da fórmula do Welfare State no âmbito do direito público, por vezes justificado pelas teses neoliberais dos desequilíbrios orçamentários.

Em complemento, agora encontra-se com tentáculos no âmbito privado das relação de emprego, com a inegável promoção de sua privatização, flexibilização legal que venha arrefecer a publicização do Direito do Trabalho pela sua reaproximação com o Direito Civil, força contrária ao imperialismo da relação de emprego vivenciado no período de construção do Direito Social desde a teorização de Cesarino Júnior, um erro estratégico pela perspectiva da eficiência das políticas públicas do Estado no campo social.

Com efeito, o caos social instalado pela greve dos caminhoneiros, ocorrida em meados de 2018 no Brasil, nada mais fez do que nos aclarar sobre a fragilidade vivenciada em face das condições trabalhistas de uma massa de trabalhadores que "dirige" a economia e a própria sociedade.

Neste sentido, como solução ao movimento grevista de 2018, e pelo fato de ter sido relegado o Direto do Trabalho como uma eficiente ferramenta de intervenção social, permitiu que o Governo Federal ressuscitasse alternativas anacrônicas como o tabelamento do frete, meio de intervenção no domínio econômico flagrantemente inconstitucional por 
vulnerar a um só tempo o princípio da livre iniciativa e livre concorrência do art. 170, caput $^{39}$ e art. $173, \S 4^{\text {o40 }}$, ambos da CF.

Portanto, visando superar os problemas evidenciados com a deflagração da greve, e a insuficiência das soluções implementadas pelo governo federal, vez que esta ainda mantém em desequilíbrio as partes envolvidas, pois muitos trabalhadores da categoria dos transportes se encontram em enquadramento de autônomos. Nosso intento é encetar a aplicação residual das regras do Código Civil visando abranger não apenas a relação de emprego, mas o seu gênero maior, que se perfaz pela relação de trabalho, garantindo-se desta forma, maior proteção a esta categoria de trabalhadores, bem como todos aqueles que se encontrem em situação equivalente, difundindo tal ideia como uma alternativa legal e doutrinariamente possível que fomenta a socialidade da relação de trabalho fundada no dirigismo estatal, promotora da equidade e equilíbrio contratual.

\section{REFERÊNCIAS BIBLIOGRÁFICAS}

ADAMS, Charles. For good and evil: the impact of taxes on the course of civilization. 2 ed. Madison Books: Maryland, 1999.

BALEEIRO, Aliomar. Uma introdução à ciência das finanças. 18. ed. Rio de Janeiro: Forense, 2012.

BARROS, Alice Monteiro de. Curso de direito do trabalho. 10. ed. São Paulo: LTr, 2016.

BRAGHINI, Marcelo. Reforma Trabalhista: flexibilização das normas sociais do trabalho. São Paulo: LTr, 2017.

BRASIL. Universidade Federal de Minas Gerais. Lei Le Chapelier (1791) (14 de junho). Tradução de Luiz Arnaut. Disponível em: http://www.fafich.ufmg.br/hist_discip_grad/LeiChapelier.pdf. Acesso em: 08 out. 2018.

CESARINO JÚNIOR, A. F. Sobre o conceito do "direito social". Revista da Faculdade de Direito, Universidade de São Paulo, 36(1-2), 117-132, 1941.

\footnotetext{
${ }^{39}$ É o teor do art. 170 da Constituição: "A ordem econômica, fundada na valorização do trabalho humano e na livre iniciativa, tem por fim assegurar a todos existência digna, conforme os ditames da justiça social, observados os seguintes princípios".

${ }^{40}$ Art. 173, § 4 $4^{\circ}$ da CF: "lei reprimirá o abuso do poder econômico que vise à dominação dos mercados, à eliminação da concorrência e ao aumento arbitrário dos lucros".
} 
DE LA CUEVA, Mário. El nuevo derecho mexicano del trabajo. México, Porrúa, 1972.

DELGADO, Maurício Godinho. Curso de direito do trabalho. 13. ed. São Paulo: LTr, 2014. A reforma trabalhista no brasil. São Paulo: LTr, 2017.

FOME de Poder (Nome Original: The Founder). Direção: John Lee Hancock. Produção: Aaron Ryder, Don Handfield e Jeremy Renner. Interpretes: Michael Keaton, Laura Dern, Patrick Wilson e Linda Cardellini. Roteiro: Robert Siegel. [S.I.]: FilmNation Entertainment, 2017. 1 bobina cinematográfica, $115 \mathrm{~min} ., 35 \mathrm{~mm}$.

FORBATH, William E. Forbath; ROGERS, Brishen. A New Type of Labor Law for a New Type of Worker. In: The New York Times, Opinion - OP-ED CONTRIBUTORS, Nova York, 04 de setembro de 2017. Disponível em: https://www.nytimes.com/2017/09/04/opinion/labor-lawsworkers.html. Acesso em 20 out. 2018.

FRANÇA. Declaração Universal dos Direitos do Homem e do Cidadão. 1789. Disponível em: http://www.dhnet.org.br/direitos/anthist/dec1793.htm . Acesso em: 02 out. 2018.

FUKUYAMA, Francis. Political order and political decay: from the industrial revolution to the globalization of Democracy. New York: FSG books, 2014.

GRAU, Eros Roberto. A Ordem Econômica na Constituição de 1988.16. ed. São Paulo: Malheiros, 2013.

IBRAHIM, Fábio Zambbitte. A Previdência Social no Estado Contemporâneo. Rio de Janeiro: Impetus, 2011.

. Curso de Direito Previdenciário.14. ed. Rio de Janeiro: Impetus, 2009.

MAGANO, Octavio Bueno. Manual de direito do trabalho. Parte Geral. 2. ed. São Paulo: LTr, 1980.

MANNRICH, Nelson. A reforma do mercado de trabalho: a experiência italiana. São Paulo: LTr, 2010.

A modernização do contrato de trabalho. São Paulo: LTr, 1998.

MORAES FILHO, Evaristo de; MORAES, Antonio Carlos Flores de. Introdução ao direito do trabalho. 6. ed. São Paulo: LTR, 1993.

MORAIS FILHO, Evaristo de. O problema do sindicato único no Brasil: seus fundamentos sociológicos. 2 ed., São Paulo, Alfa-Omega, 1978.

NASCIMENTO, Amauri Mascaro. Iniciação ao direito do trabalho. 39. ed. São Paulo: LTr, 2014.

Compêndio de direito sindical. 8. ed. São Paulo: LTr, 2015.

Direito contemporâneo do trabalho. São Paulo: Saraiva, 2011. 
NASCIMENTO, Amauri Mascaro; NASCIMENTO, Sônia Mascaro. Curso de direito do trabalho: história e teoria geral do direito do trabalho: relações individuais e coletivas do trabalho. 29. ed. São Paulo: Saraiva, 2014.

ROBINSON, James A. Why nations fail: the origins of Power, posperity, and poverty. New York: Crown Business, 2012.

ROBORTELLA, Luiz Carlos Amorim. O moderno direito do trabalho. São Paulo: LTr, 1994. O direito do trabalho na empresa e na sociedade contemporânea. São Paulo: LTr, 2010.

SEN, Amartya. Desenvolvimento como liberdade. São Paulo: Companhia das Letras, 2010.

SMITH, Adam. A riqueza das nações. 2. ed. São Paulo: WMF Martins Fontes, 2013.

SOUTO MAIOR, Jorge Luiz. O direito do trabalho como instrumento de justiça social. São Paulo: LTr, 2000.

. Dumping social nas relações de trabalho. 2. ed. São Paulo: LTr, 2014.

SÜSSEKIND, Arnaldo. Curso de direito do trabalho. 2. ed. Rio de Janeiro: Renovar, 2004.

Direito internacional do trabalho. 3. ed. São Paulo: LTr, 2000.

VIANNA, Segadas et al. Instituições de direito do trabalho. 17. ed. vol. 1. São Paulo: LTr, 1997. 